\title{
Design and Implementation of an Isolated Power Factor Correction using Full Bridge Topology
}

\author{
Tejaswini S. Jadhav ${ }^{1}$, A.M. Chole ${ }^{2}$, B.T. Deshmukh ${ }^{3}$ \\ M.E (EPS), Department of EEP, Jawaharlal Nehru Engineering College, Aurangabad, Maharashtra, India ${ }^{1}$ \\ Asst. Professor, Department of EEP, Jawaharlal Nehru Engineering College, Aurangabad, Maharashtra, India ${ }^{2,3}$
}

\begin{abstract}
Power Factor, the ratio between the real or average power and the apparent power forms a very essential parameter in power system. It is indicative of how effectively the real power of the system has been utilized. With rapid development in power semiconductor devices, the usage of power electronic systems has expanded to new and wide application range that include residential, commercial, aerospace and many others. Power electronic interfaces e.g. switch mode power supplies (SMPS) have proved to be superior over traditional linear power supplies. However, their non-linear behaviour puts a question mark on their high efficiency. The current drawn by the SMPSs from the line is distorted resulting in a high Total Harmonic Distortion (THD) and low Power Factor (PF). Individually, a device with harmonic current does not pose much serious problem however when used on a massive scale the utility power supply condition could be detoriated. Other adverse effects on the power system include increased magnitudes of neutral currents in three-phase systems, overheating in transformers and induction motors etc. Hence, there is a continuous need for power factor improvement and reduction of line current harmonics. Development of new circuit topologies and control strategies for Power Factor Correction (PFC) and harmonic reduction has become still more essential with the introduction of strong technical IEC standards. These is the review paper in which comparison for circuit with PFC and circuit without PFC by using MATLAB/SIMULINK.
\end{abstract}

Index Terms: Power factor, Switch mode power supply (SMPS), power factor correction.

\section{INTRODUCTION}

The power factor of an AC electric power system is defined as the ratio of the real power flowing to the load to the apparent power in the circuit, and is a dimensionless number between 0 and 1 . Real power is the capacity of the circuit for performing work in a particular time. Apparent power is the product of the current and voltage of the circuit. Due to energy stored in the load and returned to the source, or due to a non-linear load that distorts the wave shape of the current drawn from the source, the apparent power will be greater than the real power. In an electric power system, a load with a low power factor draws more current than a load with a high power factor for the same amount of useful power transferred. The higher currents increase the energy lost in the distribution system, and require larger wires and other equipment. Because of the costs of larger equipment and wasted energy, electrical utilities will usually charge a higher cost to industrial or commercial customers where there is a low power factor. Linear loads with low power factor (such as induction motors) can be corrected with a passive network of capacitors or inductors. Non-linear loads, such as rectifiers, distort the current drawn from the system.

In such cases, active or passive power factor correction may be used to counteract the distortion and raise the power factor. The devices for correction of the power factor may be at a central substation, spread out over a distribution system, or built into power-consuming equipment. This project aims to develop a circuit for PFC using passive filtering approach; it shall be based on an optimized power sharing strategy to improve the current quality and at the same time reduce the switching losses. The work initially involves simulation of basic power electronic circuits and the analysis of the current and voltage waveforms. It starts with simple circuits with a gradual increase in complexity by inclusion of new components and their subsequent effect on the current and voltage waveforms. We focus on the objective of improving the input current waveform i.e. making it sinusoidal by tuning the circuits. All the simulation work is done in MATLAB Simulink environment and the results are attached here with.

\section{POWER FACTOR}

Power factor is defined as the cosine of the angle between voltage and current in an ac circuit. There is generally a phase difference $\varnothing$ between voltage and current in an ac circuit. $\cos \varnothing$ is called the power factor of the circuit. If the circuit is inductive, the current lags behind the voltage and power factor is referred to as lagging. However, in a 
capacitive circuit, current leads the voltage and the power factor is said to be leading. In a circuit, for an input voltage $\mathrm{V}$ and a line current I,

VIcos $\emptyset$-the active or real power in watts or $\mathrm{kW}$.

VIsin Ø- the reactive power in VAR or kVAR.

VI- the apparent power in VA or kVA.

Power Factor $=\frac{\text { Real Power }}{\text { Apparent Power }}$

\section{A. Power factor Correction}

Power factor correction is the method of improving the power factor of a system by using suitable devices. The objective of PFC circuit is to make the input to a power supply behave like purely resistive or a resistor. When ratio between voltage and current is constant, then the input will be resistive hence the power factor will be 1.0. When the ratio between voltage and current is other than 1 due to the presence of nonlinear loads, the input will contain phase displacement, harmonic distortion and thus the power factor gets degraded.

\section{B. Source of poor power factor}

Now go through the reasons behind poor power factor:

1] Inductive Load: In most of industries consist of inductive load for example induction motor, transformer, arc lamps, electric furnace etc as result power factor is not unity. Because these component draws magnetic current to produce magnetic field.

2] Variation In Power System: In power system load is not constant which varies accordance's with time. At low load or peak period the voltage and current are increases so the power factor will be poor.

3] Harmonic Current: Harmonic current is generated due to non-linear load as a result there is poor power factor in system.

4] Power Imbalance: A 3 phase power imbalance is occurred due to improper wiring or electrical accidents as a result poor power factor in system.

\section{Need of Power Factor Correction}

The benefits that can be achieved by applying the correct power factor correction are.

1] Due to high power factor a reduction in electricity charges.

2] High power factor reduces the $I^{2} R$ losses of transformer.

3] High power factor reduces the size of conductor and cable as a result cost of copper also reduces.

4] High power factor increases the efficiency of system or devices.

5] High power factor increase the system load capacity without additional system.

6] High power factor reduces the amount of heat generated in cables, transformers, switchgear and other equipment.

\section{Types of Power Factor Correction}

Power Factor Correction can be classified as two types:

1] Passive PFC

2] Active PFC

I] Passive Power Factor Correction

In Passive PFC, in addition to the diode bridge rectifier, passive elements are introduced to improve the nature of line current. By using this, power factor can be increased to a value of 0.7 to 0.8 approx. as the voltage level of power supply increases the size of PFC components also increase. The idea of passive PFC is to filter out the harmonic current by use of low pass filter and only allow $50 \mathrm{~Hz}$ power frequency wave to increase the power factor. Passive PFC is not reliable method for power factor Correction. As name indicate itself in that means it uses passive elements such as inductor and capacitor for power factor correction.Fig.1.shows the passive power factor correction technique. Which consists of inductor, bridge rectifier and capacitor. In these system inductor is connected at input side and which is in series with line voltage. When the inductor has higher value it stores sufficient energy to maintain the rectifier in continuous conduction mode for half cycle and reduces the harmonic distortion.

Passive PFC is efficient due to:

1] It is simple in construction.

2] Reliable.

3] Rugged in construction. 


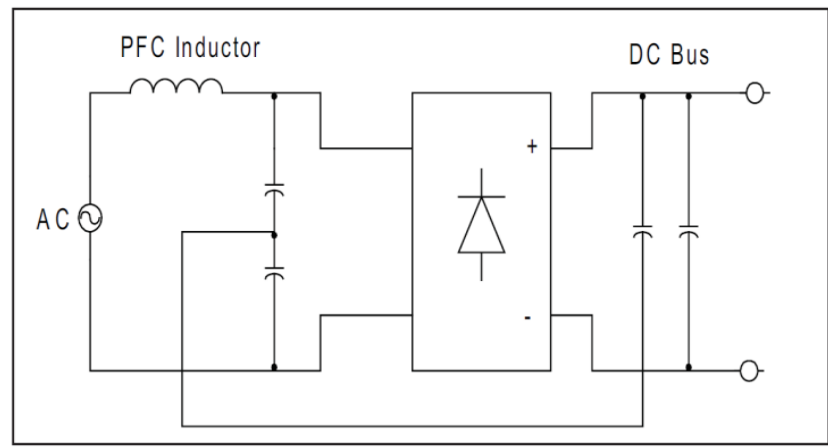

Fig.1. Passive power factor correction technique

II] Active Power Factor Correction

Fig.2. shows active power factor correction technique. In these technique power factor will be improve using active component such as boost converter, MOSFET, IGBTs etc. In Fig.2. input is applied to the bridge rectifier which produces a full wave rectified output. No current flowing through the holdup capacitor till the line voltage is boost above the voltage present in the holdup capacitor. This technique consists of control circuits to adjust the boost voltage and maintain the sinusoidal input current. But these technique has some drawbacks such as line frequency components are large and heavy, cannot completely correct nonlinear loads - 95\% maximum power factor, audible noise, complex.

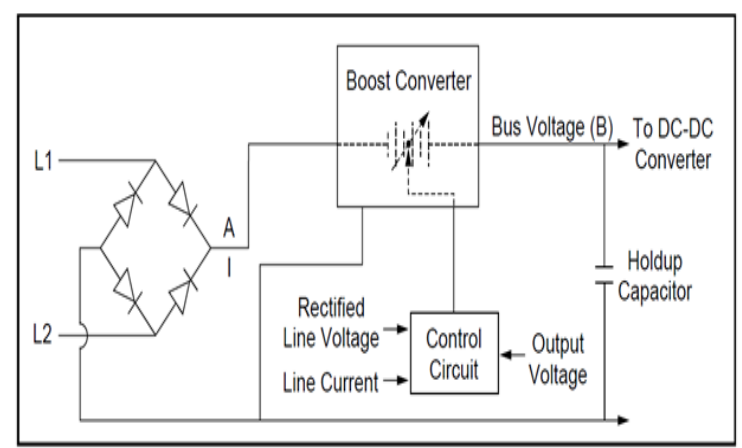

Fig.2. Active power factor correction technique

\section{SIMULINK MODEL}

A. Model And Simulation Results without PFC

This paper involves simulation of basic power electronic circuits and the analysis of the current and voltage waveforms. It starts with simple circuits with a gradual increase in complexity by inclusion of new components and their subsequent effect on the current and voltage waveforms. We focus on the objective of improving the input current waveform i.e. making it sinusoidal by tuning the circuits. All the simulation work is done in MATLAB Simulink. Fig.3. Shows the power factor correction technique without PFC circuit.

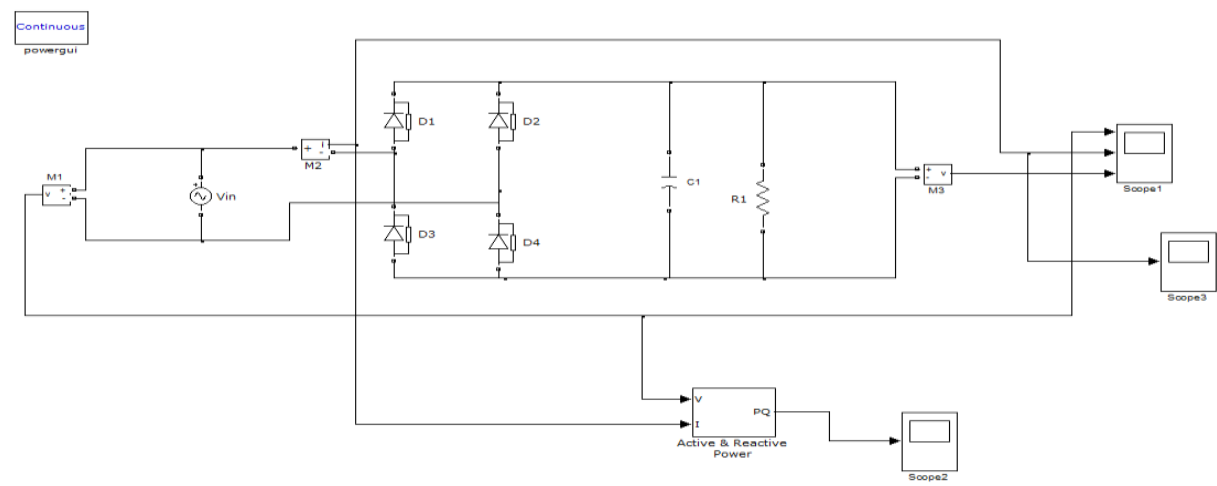

Fig.3. Power factor correction technique without PFC circuit 
International Journal of Innovative Research in Electrical, Electronics, Instrumentation and Control Engineering

ISO 3297:2007 Certified

Vol. 5, Issue 6, June 2017

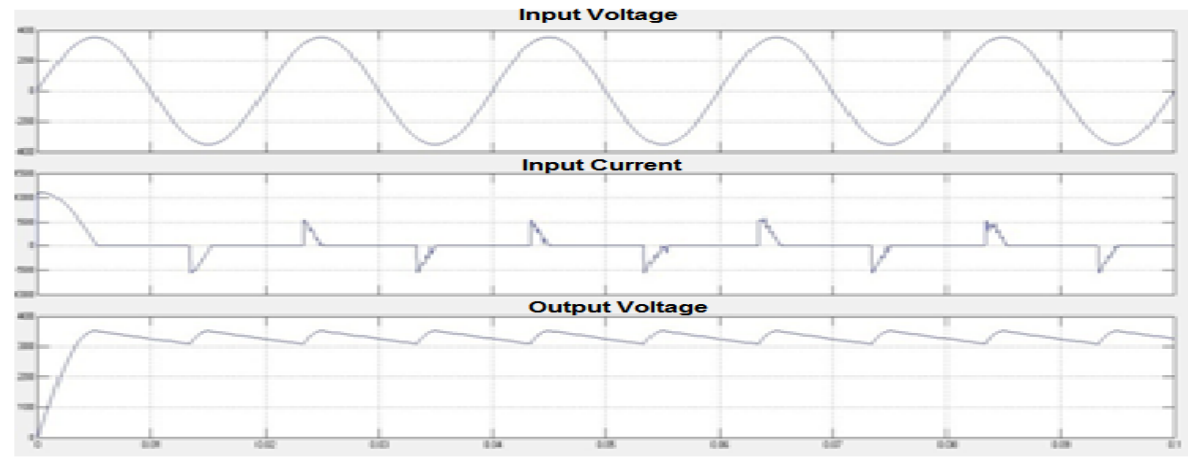

Fig.4.Simulation Result without PFC

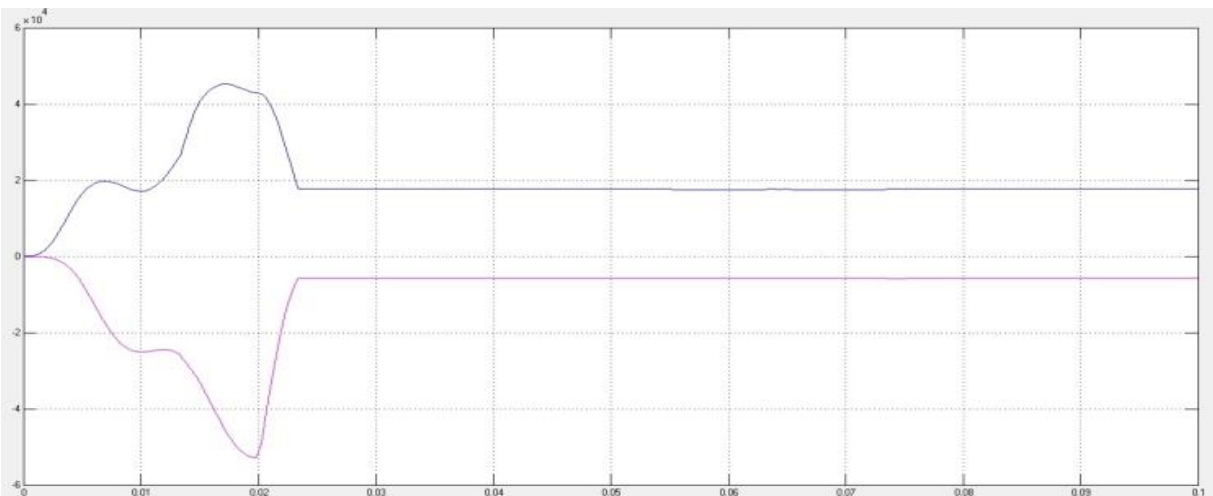

Fig.5. Active And Reactive Power without PFC
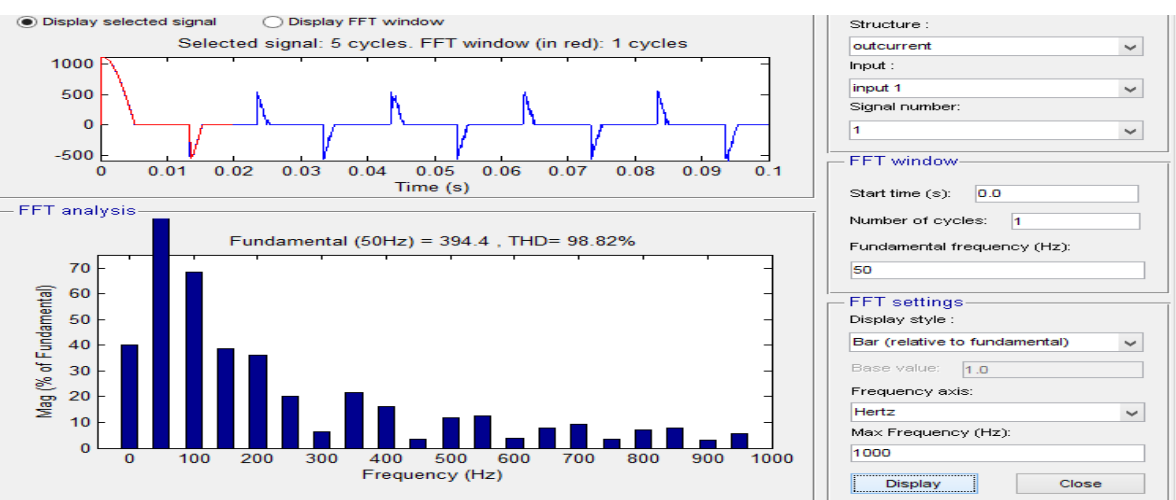

Fig.6.FFT Analysis of Input Current without PFC

B. Model and Simulation Results with PFC Circuit:

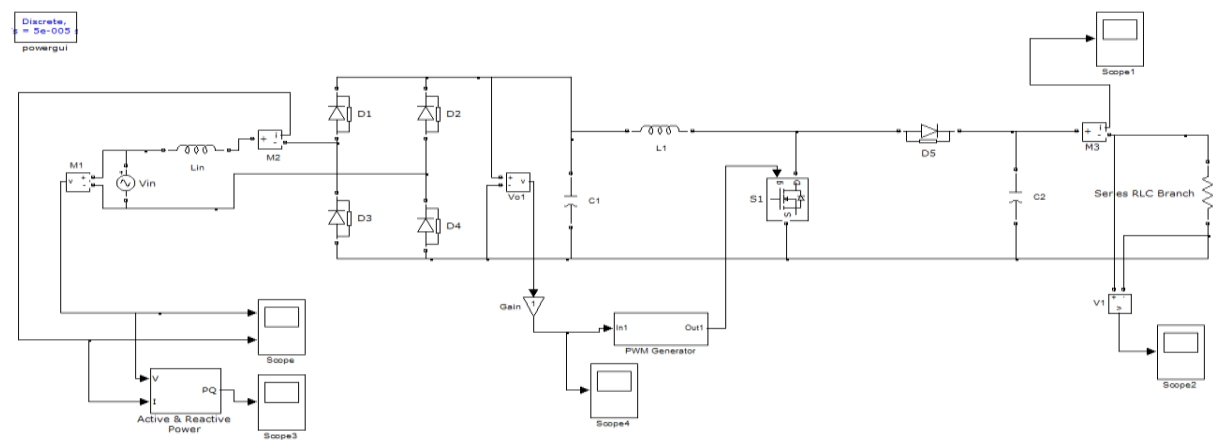

Fig.7. Power factor correction technique with PFC circuit 


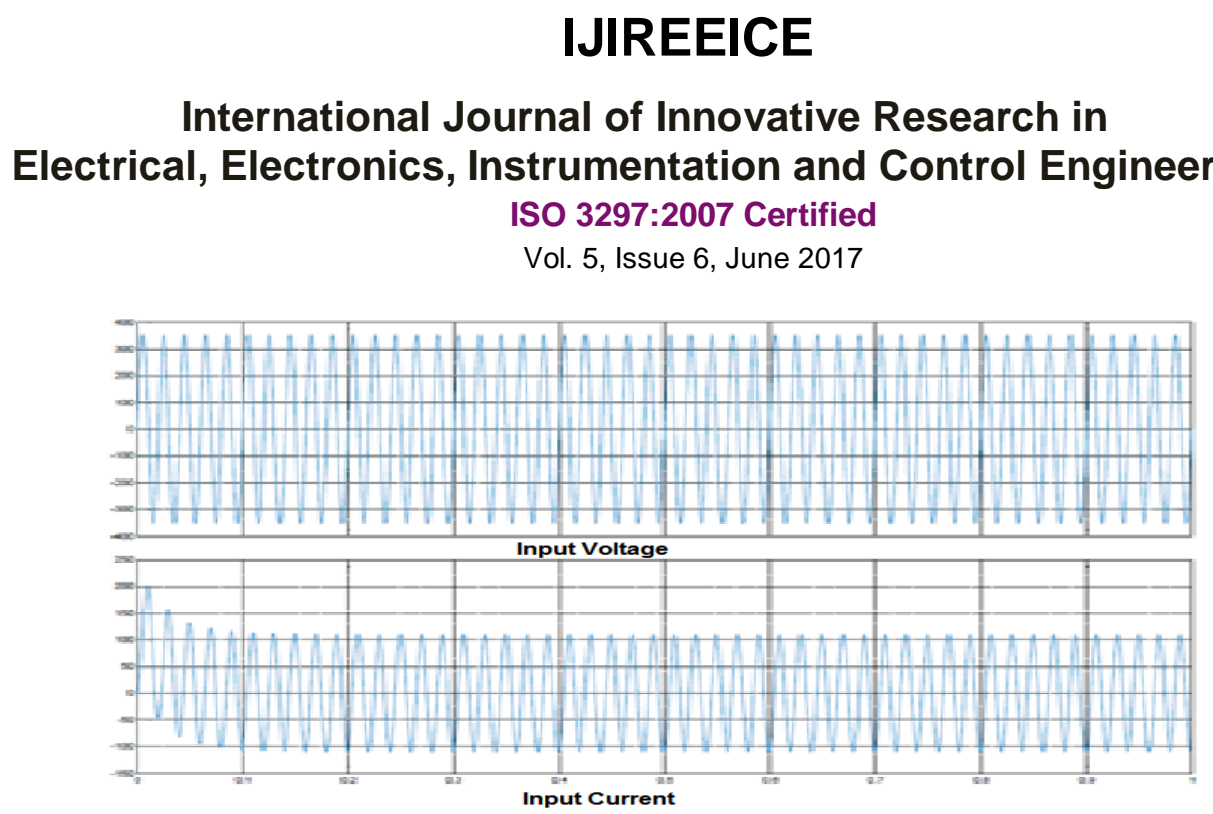

Vol. 5, Issue 6, June 2017

Fig.8.Simulation Result with PFC

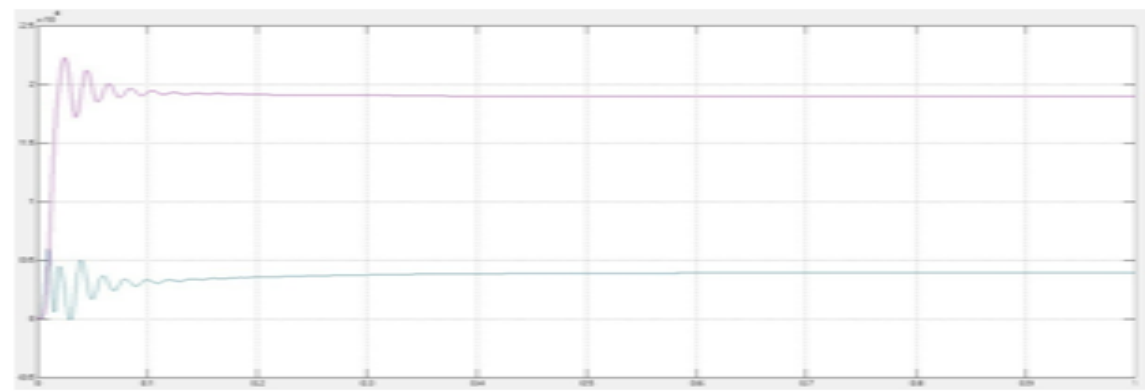

Fig.9. Active And Reactive Power with PFC

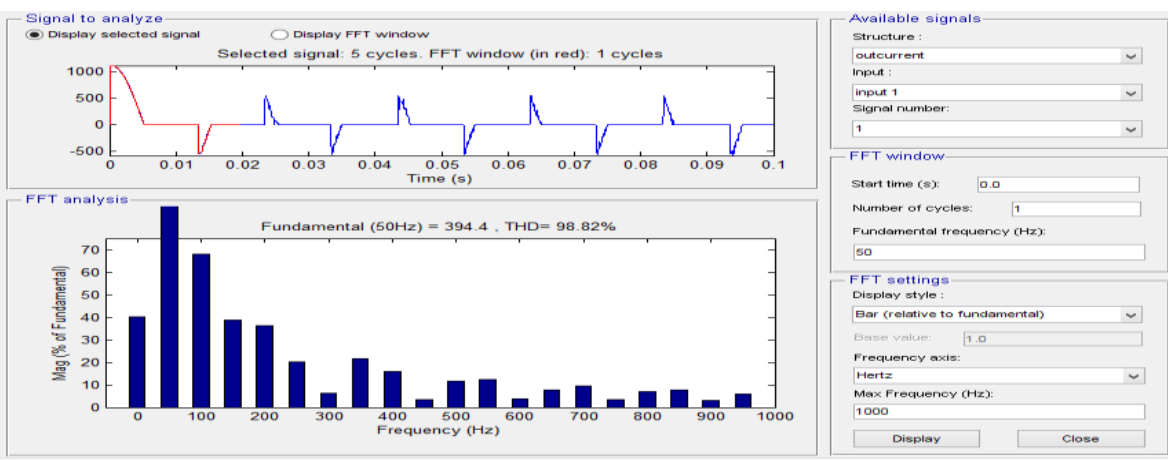

Fig.10.FFT Analysis Of Input Current with PFC

\section{CONCLUSION}

Power factor is depending on load connected to supply, with non-linear loads the power factor degrading and harmonics exceeds and when the THD is higher the power factor is low. So to make the power factor unity some reactive elements and switches are used thus unity power factor is achieved. The main objective throughout the project has been to improve the input Power Factor with simultaneous reduction of input current harmonics. Simulations were initially done for elementary rectifier circuits without employing any PFC circuit and with PFC circuit.

\section{REFERENCES}

[1] Active PFC for power electronic supplies, Application Note VICOR.

[2] Rashid M., Power Electronics Handbook.

[3] Fairchild Semiconductor- "Application Note 42047, Power Factor Correction (PFC) Basics"-www.fairchildsemi.com

[4] Dixon, L.; Average Current Mode control of switching mode power supplies, Application Note, Unitrode, U-140

[5] Parillo, F.; Dual Boost High performances Power Factor Correction Systems (PFC),

[6] R. W. Erickson, Fundamentals of power electronics. New York, NY, USA, Chapman

[7] N. Mohan, ET el. Power Electronics: Converters, Applications, and Design. New York: NY, USA, John Wiley \& Sons, Inc., 1995. 